\title{
Forests and trees in firearm injury research
}

\author{
K Kaufer Christoffel
}

In this issue of Injury Prevention, Hootman and colleagues present the latest information on non-fatal, non-gunshot injuries related to guns in the United States. ${ }^{1}$ The report is the latest in a series of snapshots that investigators at the United States Centers for Disease Control (CDC) have added to the ever-so-slowly evolving panoramic picture of our country's unique burden of gun injury (see http://www.cdc.gov/ ncipc). The paper is of interest both for what it says and what it does not say.

\section{What is said}

The authors set the stage by reminding readers of the large, albeit recently falling, number of gunshot deaths and injuries in the United States each year. Then, using carefully constructed emergency department based estimates, they focus on the $16 \%$ of all medically treated gun related injuries due to mechanisms other than gunshot wounds. The authors observe that the risk for these injuries parallels that of gunshot wounds (males, youth, AfricanAmericans) and identify possible prevention approaches for the unintentional injuries.

This study involved the development of two potentially important new coding schemes, that detail both mechanism of injury and activity at the time of injury.

\section{What is missing, datawise}

This research is based on data from the Consumer Product Safety Commission's National Electronic Injury Surveillance System (NEISS). The authors acknowledge the limitations of the data, which exclude non-medically attended injuries, does not permit local incidence estimates, relies for injury history on (often incomplete) medical recording, and suffers from missing information.

Other factors also limit the accuracy of the information presented. Non-powder firearms (airguns, "BB guns"), were excluded, though in terms of non-gunshot events are more like powder guns than not. ${ }^{2}$ This was due to small NEISS counts for these (J Mercy, personal communication, 15 August 2000). Injuries related to military contexts were excluded. Delayed deaths due to the non-gunshot wound injuries could not be identified.

\section{What is not said}

Fine attention to the detailed questions at hand and a data focused discussion section, make it possible to ignore the big picture, of which this snapshot is just one small part.

\section{DATA LIMITATIONS}

The authors do not discuss why they are using the NEISS data, with all its limitations, rather than another, more complete, more detailed, data source. The reason is that although firearm injuries are the second leading cause of injury death in the United States, there is not yet a national system to track even the deaths - for example, one akin to the Fatality Analysis Reporting System that has been so useful in understanding motor vehicle injuries.

The reason for this dearth of detailed and reliable data is that political forces in the United States-notably the National Rifle Association-have effectively worked to assure that research on firearms is limited. This has sharply curtailed original data collection, and has slowed the development of state and national surveillance systems. (At the moment, the development of basic public health surveillance of gun injuries is being underwritten by philanthropy!)

This anti-information campaign has restricted research on firearm injuries at the CDC's National Center for Injury Prevention and Control (NCIPC). A few years ago, Congress removed the mere $\$ 2.6$ million that had been designated for firearm related research at NCIPC. At the same time, legislation was passed that restricts the CDC's work in this area: "None of the funds made available for injury prevention and control at the Centers for Disease Control and Prevention may be used to advocate or promote gun control". NCIPC has therefore limited the scope of its intramural research on firearm injuries largely to description using available data.

\section{EXPOSURE TO GUNS}

Exposure to guns is discussed only to explain the exclusion of military training related injuries (due to increased gun exposure compared with the civilian population). The need for this exclusion is debatable, because security guards and other high exposure groups (for example, hunters) were not excluded. The most serious effect of this exclusion is to give the impression that it corrects for exposure in this study, which it does not.

Exposure is always an important issue in any type of injury research. When guns are around, they tend to be used in varied ways: not only for the home protection or hunting for which they 
are kept, but also to defend against real or imagined dangers and to aggress. Whenever they are used, they substantially raise the risk that serious injury will occur, compared with other tools that might be used in their absence (for example, plates, knives, and fists). It is necessary to understand the effects of exposure patterns on risk. For example, men are more likely to own and use guns, which presumably explains a lot of the male predominance among those injured by guns.

Exposure is a particularly crucial issue in this paper because some of the types of injuries that are described in the most detail involve an exposed population that is much smaller than the general population. The presentation of injury rates using the entire population as the denominator inevitably gives misleadingly low rates. ${ }^{3}$ For example, only $20 \%$ or less of the population in the United States engages in hunting (T Smith, National Opinion Research Center, personal communication, 9 August 2000). Thus the injury rate for the exposed population is five times what it would be if the entire population were exposed.

In the results and discussion sections of the paper by Hootman et al, attention is focused on hunting and target shooting injuries. The report can be interpreted as reassurance that guns are safe for play. The implication appears to be that guns are not a problem, but rather the situations in which they are used. If, on the other hand, airgun and military injuries were included, and the rate calculations were corrected for exposure, the rates would be much higher and the message could be quite different.

Although exposure matters a lot, it is all but ignored because good data on exposure are not available. The authors do not call attention to this, perhaps because it could be construed as suggesting the possible relevance of reducing exposure to guns, which some might call "gun control". As noted, CDC researchers are not allowed to appear to do so.

\section{Approaches to preventing the violence related injuries}

There is a full discussion of prevention approaches for the unintentional injuries studied. It emphasizes education of shooters and creative engineering approaches, for example, tiny airbags for the eyeball on rifle scopes, to prevent ocular injuries related to gun recoil. However, the other Es of injury preventionenforcement and evaluation-are not explored. Perhaps here too there was a concern that this would be getting too close to "gun control".

That probably is the reason for the authors' staying away from discussing violent injuries. Education on gun use is not likely to reduce these, and engineering solutions are not obvious either. In this realm, the key interventions are likely to involve reductions in gun access. The CDC based authors can't, as the kids say, "go there". (To be sure, pistol whipping is not a good reason to reduce gun access; but if gun access were reduced, the particularly heavy and handy blunt objects would be less available for use in this way.)

\section{Where does this research lead?}

The authors do not identify the interesting research directions that this paper points to. For example, reports on the performance characteristics of the new codes developed will be of great interest. So will research on gun exposure. Comprehensive surveillance is needed. One wonders if the inclusion of such a list would have required clearance: to assure that it did not seem to touch issues that might be seen as related to gun control.

Thus do the politics of guns reach into the science of injury control. If this were to occur in other countries, Americans would be shocked. And we should be shocked that it occurs in the United States.

\section{How do we make sense of this report?}

This report is an up-close, if slightly out-offocus, snapshot of one tree in the forest of gun injuries in the United States. It is an interesting tree. But we cannot interpret the snapshot without understanding the forest. As a result, the paper does not lead to solid conclusions about how we can use the information presented to better understand the risks compared with the benefits of guns in life in the United States.

In the light of all that, I think the take home lessons from this study are these:

- Non-gunshot wounds do contribute to the total burden of gun related injuries, and should not be ignored.

- Most of those injuries are due to violence.

- Only a small proportion are due to recreational gun use, and the rates of those should be corrected for exposure to guide prevention planning.

- Approaches to preventing these and other gun injuries must include all the Es of injury prevention.

- Better data are needed to effectively apply those Es in order to prevent these injuries, and that is also true for the vast majority of gun related injuries that are due to gunshots.

- The political shackles on CDC research on gun injury need to be removed, in the interests of science, the bedrock of effective prevention. The extensive expertise available there should be used not only for close-ups of unique gun related injury trees, but also freed to map the thick forest of gun injury, in which so many have gotten lost.

There is work afoot to address the serious problem of inadequate data. For information on this, please consult the "Just the Facts" section of the web page of the Handgun Epidemic Lowering Plan (HELP) Network at www.helpnet work.org. (HELP is the international network of medical and allied organizations addressing gun violence as a public health problem.)

1 Hootman JM, Annest JL, Mercy JA, et al. National estimates of non-fatal firearm related injuries other than gunshot wounds. Inj Prev 2000;6:268-74.

$2 \mathrm{BB}$ and pellet gun-related injuries-United States, June 1992-May 1994. MMWR Morb Mortal Wkly Rep 1995;44: 909-13.

3 Senturia YD, Binns HJ, Christoffel KK, et al. In-office survey of childrens hazard exposure in the Chicago area: agespecific exposure information and methodological lessons. $\mathcal{f}$ Dev Behav Pediatr 1993;14:169-75. 